\title{
EVIDENCE FROM TWO LARGE FIELD EXPERIMENTS THAT PEER COMPARISON FEEDBACK CAN REDUCE RESIDENTIAL ENERGY USAGE
}

\author{
Ian Ayres \\ Sophie Raseman \\ Alice Shih \\ Working Paper 15386 \\ http://www.nber.org/papers/w15386 \\ NATIONAL BUREAU OF ECONOMIC RESEARCH \\ 1050 Massachusetts Avenue \\ Cambridge, MA 02138
}

September 2009

Special thanks to Tyler Curtis and Alex Laskey from Positive Energy/oPower for contributing criticism to earlier drafts. The views expressed herein are those of the author(s) and do not necessarily reflect the views of the National Bureau of Economic Research.

NBER working papers are circulated for discussion and comment purposes. They have not been peerreviewed or been subject to the review by the NBER Board of Directors that accompanies official NBER publications.

(C) 2009 by Ian Ayres, Sophie Raseman, and Alice Shih. All rights reserved. Short sections of text, not to exceed two paragraphs, may be quoted without explicit permission provided that full credit, including (๑) notice, is given to the source. 
Evidence from Two Large Field Experiments that Peer Comparison Feedback Can Reduce

Residential Energy Usage

Ian Ayres, Sophie Raseman, and Alice Shih

NBER Working Paper No. 15386

September 2009

JEL No. O13

\section{ABSTRACT}

By providing feedback to customers on home electricity and natural gas usage with a focus on peer comparisons, utilities can reduce energy consumption at a low cost. We analyze data from two large-scale, random-assignment field experiments conducted by utility companies providing electricity (the Sacramento Municipal Utility District (SMUD)) and electricity and natural gas (Puget Sound Energy (PSE)), in partnership with a private company, Positive Energy/oPower, which provides monthly or quarterly mailed peer feedback reports to customers. We find reductions in energy consumption of 1.2\% (PSE) to $2.1 \%$ percent (SMUD), with the decrease sustained over time (seven months (PSE) and twelve months (SMUD)).

Ian Ayres

Yale Law School

P.O. Box 208415

New Haven, CT 06520-8415

and NBER

ian.ayres@yale.edu

Sophie Raseman

Yale Law School

127 Wall Street

New Haven, CT 06511

sophie.raseman@yale.edu
Alice Shih

Yale Law School

127 Wall Street

New Haven, CT 06511

alice.shih@yale.edu 


\section{Evidence from Two Large Field Experiments that Peer Comparison Feedback Can Reduce Residential Energy Usage}

\section{Introduction}

In this paper we analyze two field experiments conducted on a total of approximately 75,000 household customers of two utilities, the Sacramento Municipal Utility District (SMUD) and Puget Sound Energy (PSE). These utilities, in partnership with a private company, Positive Energy/oPower, randomly assigned a subset of these households to periodically receive mailed reports comparing their energy usage to that of nearby neighbors in similarly sized houses. We find that households receiving Positive Energy/oPower's reports make significant and lasting reductions in their energy consumption.

Studies that have tested the impact of peer comparisons on conservation have had mixed results. For example, Goldstein, Cialdini, and Griksevicius (2008) have found that social norms can increase towel reuse by hotel guests. Yet, in a literature review of the effect of feedback on home energy consumption, Fischer (2008) notes that of the dozen studies that she reviews that test the impact of comparisons to others, none had shown an effect. She attributes the failure to the "boomerang" problem, where informing individuals of typical peer behavior inadvertently inspires those who have been under-estimating the prevalence of an activity to increase the unwanted behavior. Cialdini, Kallgren, and Reno (1991) argue that combining injunctive norms (norms that express social values rather than actual behavior) with descriptive norms can neutralize the boomerang effect. Schultz, Nolan, Cialdini, Goldstein, and Griskevicius (2007) conducted a randomized field study in San Marcos, California, of the effectiveness of social norms messaging (alongside energy-saving tips) to reduce home energy consumption. They found that combining the descriptive and injunctive messages (in this case, the emoticons $;$ and (:) ) lowered energy consumption and reduced the undesirable boomerang effect.

The Positive Energy/oPower experiments build on the findings of the San Marcos study. As in the San Marcos study, the Positive Energy/oPower reports use descriptive norms as well as injunctive norms, such as $:$ emoticons, to reduce consumption and in order to counteract the boomerang effect. The Positive Energy/oPower experiments reported here, however, go beyond 
the San Marcos experiment in a number of ways. First, the Positive Energy/oPower experiments have a significantly larger sample size than in San Marcos, which included 290 households vs. 35,000 in the SMUD study and 40,000 in the PSE study. Second, the Positive Energy/oPower studies also allow us to test multiple new aspects of the dynamics of energy use feedback:

- Measuring longer term impacts. Whereas the San Marcos study's observation period was only one month, the SMUD and PSE experiments have twelve and seven months of data, respectively.

- Measuring daily impacts. Unlike the San Marcos study, the PSE experiment gives access to daily energy readings.

- Measuring impacts on both electricity and natural gas. The PSE experiment tested the effect of feedback on both electricity and natural gas usage, allowing a fuller picture of household energy use.

- Measuring impacts of different message frequencies (quarterly vs. monthly), different report content, and different envelope sizes.

Moreover, the Positive Energy/oPower experiments were conducted using a more realistically scalable intervention. Instead of mailed reports, the San Marcos study used hanging doorknockers with hand-drawn emoticons. Together, the SMUD and PSE experiments provide compelling evidence that properly framed peer comparisons can predictably lower energy consumption, particularly of the highest energy using households.

\section{SMUD Experiment}

Experimental design. The SMUD messaging experiment began in April 2008 and is still ongoing; the results presented in this paper cover the period from April 2008 through April 2009. ${ }^{1}$ The sample includes 85,000 households who are customers of SMUD. To select participants, Positive Energy/oPower filtered by census tract within SMUD's footprint to maximize the number of single family homes with more than twelve months of billing history,

\footnotetext{
${ }^{1}$ All the data in this paper, including data originally obtained from the utilities themselves as well as from third parties, was generously provided to the authors by Positive Energy/oPower. SMUD has contracted with ADM \& Associates to independently assess the success of the program. In addition, Positive Energy/oPower engaged Summit Blue to do its own evaluation of the SMUD result in May 2009. PSE plans to select a third party in October 2009 to conduct program measurement and verification services.
} 
that were on standard rate plans (non-medical rate, non-photovoltaic), and that had a matching parcel record with details about the home, such as house size and value.

Once participants were selected, the randomization process used "batch" assignment: homes were randomly assigned to the treatment and control groups in 959 batches of census blocks. These "batch blocks" consist of 50 to 100 homes. 35,000 households were assigned to the treatment group, and 50,000 were assigned to the control. Positive Energy/oPower used this assignment methodology to increase the likelihood that neighbors would receive reports and have the opportunity to discuss the reports with each other, thereby increasing the motivation for taking actions to reduce home electricity consumption. The batch approach did have a drawback, however, in that treatment and control groups differed on some pre-treatment attributes.

All members of the treatment group received home energy reports on a periodic basis. Each home energy report contains four key personalized components: 1) Current period neighbor comparison: A bar chart comparing the household's recent electricity use to a group of comparable neighbors and "efficient neighbors," with both normative and injunctive messages designed to motivate action; 2) Twelve-month neighbor comparison: A chart comparing the household's electricity usage to its comparable neighbors and "efficient neighbors" over the last twelve months; 3) Personal historical comparison: A section comparing the household's usage in the current year by month with the same months from the previous year; 4) Targeted energy efficiency advice: tips selected based on the household's energy use pattern, housing characteristics, and household demographics. All reports were printed in color on a single 81/2" x 11" sheet of paper. Examples of the elements of the front page of this report are included in Appendix A3a and Appendix A3b.

The 35,000 treatment households were then assigned to different sub-treatment groups that varied the intervention. Some of the assignments were random, while others depended on household characteristics. All households (test and control) were randomly assigned to one of two different report template groups and one of two different envelope groups. The two report template groups were "graphical" and "narrative." Both templates included the same core elements, including graphs with feedback information, but the narrative version (shown in Appendix A3a and A3b) included a blurb of text explaining the charts, reinforcing the normative messages, and highlighting tips on how to save energy (including both mentioning tips in the blurbs and pointing the reader toward the personalized tips section on the back of the report). 
The two envelope types tested included a standard business "\#10" envelope (similar to the envelope used to deliver SMUD customer bills) and a larger 6" x 9" envelope. Envelope size did not affect the envelope content, which was always printed on 81/2" x 11" paper; but folded differently to accommodate the different envelope sizes.

Some elements of the treatment varied based on household characteristics. Households were assigned to receive the reports either monthly or quarterly based on historical usage levels: the 25,000 households with higher consumption levels were assigned to the monthly frequency group, while the 10,000 households using less energy $(<21.85 \mathrm{kWh} /$ day $)$ were assigned to receive the report quarterly. Households were also assigned to various tip segments based on home characteristics (i.e. presence of a pool), which allowed for characteristic-contingent targeting of energy efficiency messages.

SMUD provided the basic data on energy consumption, including historical billing information dating back to January 1, 2006 (over two years before the beginning of the treatment in April 2008). Data on household parcel characteristics (such as square footage and home values) comes from the Sacramento County Assessor's Office. ${ }^{2}$ Household demographic data (such as income level and length of residence) came from private direct marketing and data aggregation service databases.

SMUD Results. Appendix A1 investigates whether the sample is well-balanced between the control and treatment groups. Since the randomization occurred at the census level, there were statistically significant differences in some pre-treatment variables. For example, the households in the treatment group on average were 16 square feet smaller and used $.3 \mathrm{kWh}$ per day more in 2006 than the average control group households. A parallel analysis (also reported in Appendix A1) of the sub-randomization of envelope size and the graphical/narrative template shows that the data was well-balanced between these groups.

Households in the treatment group that complained about receiving the Positive Energy/oPower reports or who asked to stop receiving the report were allowed to opt out of the treatment. Only $2 \%$ of the treatment group opted out of the experiment. The following regressions, which retain these observations and which only control for pretreatment variables,

\footnotetext{
${ }^{2}$ The heating fuel type was derived from the customers' rate codes as SMUD offers lower rates to households with electric heat.
} 
should be interpreted as "intent to treat" effects. Unreported treatment on the treated (IV) estimates were of similar in size and significance. In addition, similar proportions of treatment and control households $\left(8 \%\right.$ and $7 \%$, respectively $\left(\mathrm{p}_{.}=.10\right)$ ) closed their SMUD accounts due to moving after the experiment began.

Figure 1 reports the results from monthly regressions on approximately 83,500 household observations where the log of monthly average $\mathrm{kWh}$ /day was regressed on a treatment group indicator and a constant. As shown in Figure 1, the treatment group's energy consumption (relative to the control group) moved erratically before the start of the experiment (indicated by a vertical line marking April, 2008). For example, the treatment group used more electricity than the control group in February 2007 and less in June 2007, and these differences were statistically significant. Still, even before other factors are controlled for, there was a significant drop in energy usage for the treatment group relative to the control for all the months following the initial report mailing.

To account for factors besides the reports that may be driving the change in energy usage, we control for house characteristics (square feet, age of house, presence of pool or spa, house value, gas user, census tracts), household demographics (energy usage in 2006, length of residence at particular house, number of residents, income, age, affluence), and the number of cooling degree days and heating degree days ${ }^{3}$. Figure 2 shows that after controlling for these characteristics there was no systematic difference in energy usage between the treatment and control groups. With the exception of one month in the pretreatment stage, the difference between the energy usage of the control and treatment groups is statistically insignificant, straddling 0\%. After the first reports are arrived around April 15, 2008, we observe a significant drop in the electricity consumption of treatment households relative to control households, on the order of $1 \%$ in May 2008. The rapidity of this decline suggests that the reductions may be driven by more "behavioral" changes (such as turning off lights in empty rooms) rather than "durable" changes (such as caulking or replacing inefficient appliances). There is a steady decline until August 2008, where the treatment group saw a reduction in electricity usage by more than $2.5 \%$. The gap between the usage levels of the control and treatment groups then narrows in the fall

\footnotetext{
${ }^{3}$ Cooling degree days and heating degree days are based on a base temperature of 65 degrees. For example, a day with an average temperature of 68 degrees will count as 3 cooling degree days. Similarly a day with an average temperature of 62 degrees will count as 3 heating degree days.
} 
months (Sept. 2008 - Nov. 2008), though the reductions made by the treatment group are still significantly negative. After November 2008 the effect of the treatment grows in all months except April 2009, with the greatest reduction in electricity consumption since the beginning of the experiment (greater than 2.5\%) occurring in March 2009, almost a year after the study first began.

To simultaneously investigate the impact of treatment across different months, we "stacked" the house-month data and again regressed the log of average monthly $\mathrm{kWh} /$ day for individual households on the controls reported in Table 1 (calculating standard errors by clustering on household IDs). The interaction between treatment and the variable named "After first mailing (April '08)" captures the effect of being in the treatment group after the start of the experiment. The average effect of the treatment on energy reduction is significant and robustly estimated in Table 1 at about $2.1 \%$, with or without ancillary controls.

To understand the impact of template styles and envelope size combinations, we interacted these four variables with the treatment effect (Treatment $\mathrm{x}$ After first mailing) in a regression with the full controls from Table 1. As shown in Figure 3, the graphic template sent in a \#10 business envelope reduced energy usage significantly more (nearly 3\% relative to the control group) than the other three combinations (each less than 2\%). More exploration is needed to determine why this combination of envelope size and template type had a stronger effect. One possible factor is that the \#10 business envelopes resemble the envelopes in which SMUD sends its monthly bills, which may have inspired more individuals to open and read the communication. Figure 4 reports the treatment effects separately for households who received the reports monthly or quarterly from a parallel regression with full controls and interacting the treatment effect with monthly and quarterly indicators. Because lower (higher) energy using households were non-randomly assigned to receive reports quarterly (monthly), it is not surprising that monthly recipients reduce their energy consumption by $2.35 \%$ while quarterly recipients reduced their energy consumption by about $1.5 \%$. As quarterly recipients had lower energy use to begin with, they likely had fewer opportunities to easily reduce $\mathrm{kWh}$.

We also investigated whether the treatment effect varied for households with differing demographics. To capture the effects of wealth, we used house value as a proxy. Figure 5 reports the results of interacting the treatment effect with house value quintile indicators in a regression with full controls. Every house-value quintile of the treatment group used statistically less 
electricity than the control group; however the three lower-value quintiles had a reduction greater than the average of $2.1 \%$, while the two higher quintiles saw a decrease less than the average.

We also investigated whether there were different treatment effects for households with different levels of pretreatment energy usage adjusted by house size. We created deciles of pretreatment energy usage per house square foot which was calculated using the usage fifteen months prior to experiment, and again interacted these indicators with the treatment effect in a regression with full controls. Figure 6 shows that households with larger pre-treatment usage generally experienced larger percentage reductions from receiving the reports. Reductions reported are relative to households from the same decile in the control group. In fact, the treated households in the two lowest deciles of pretreatment energy users increased their energy usage. It is possible that some of this phenomenon was driven by the fact that the households learned that their peers were consuming more electricity, in what Cialdini, Kallgren, and Reno (1991) have called the "boomerang" effect. The presence of a boomerang effect contradicts the findings Schultz, Nolan, Cialdini, Goldstein, and Griskevicius (2007) in the San Marcos study, where lower-consuming households did not increase their energy usage. This boomerang effect is not a necessary drawback of the treatment, however, as any program using peer feedback reports can always omit sending reports to the lowest-consuming households. In this case, the boomerang effect was overwhelmed by enhanced energy conservation in the other eight deciles. The highest energy users reduced their energy consumption by nearly $7 \%$ relative to high energy users who did not receive the report. It is not surprising that the households with higher historic usage per square foot should see a larger impact from the reports, since they were more likely to receive a message that they used more energy than their neighbors and were more likely to have discretionary energy use that was easy to reduce.

Table 2 estimates the potential yearly impact of the reports on both dollars saved and energy conservation if SMUD were to send the reports to all of the households in its customer base. At an average reduction of $2.35 \%$ for monthly recipients, the reports would reduce consumption $211 \mathrm{kWh}$ per year per household for a total savings of about \$31 a year per household (figures are based on SMUD system-wide average usage, which is about 2,000 kWh per year lower than the average for households in the experiment). Quarterly recipients would decrease their energy use by $130 \mathrm{kWh}$ per year for a total annual savings of $\$ 13$. If the nearly 593,000 households in SMUD's customer base received reports using the same formula by 
which SMUD treatment households were assigned to monthly or quarterly reports, we could expect to see a reduction of over 110 million $\mathrm{kWh}$ in a year - the energy equivalent of saving over 9 million gallons of gas. SMUD customers would save over $\$ 15.2$ million on their energy bills under the current SMUD rate plan. For every mailing in SMUD’s customer base, \$2.57 would be saved for monthly recipients, and $\$ 3.29$ for quarterly. Since, as shown in Figure 6, higher energy users made significantly larger reductions in energy, it is likely that that targeting reports at only higher energy consumers would be particularly cost effective. By our analysis, SMUD could achieve a significant environmental impact by sending reports to all of its customers. The reports would save the equivalent of nearly 80,000 metric tons of carbon emissions. Quarterly reports produce a bigger energy saving per mailing (the equivalent of 1.43 and 2.64 gallons of gasoline per mailing for monthly and quarterly reports respectively).

Including report information with the regular bill may make the feedback even more cost effective. However, more research is needed into this question. It remains an open question whether including the reports in the bill would in fact reduce production costs, as such integration may require significant investments to change current legacy billing systems, which are typically in black and white and do not allow for extensive customization and graphics. Secondly, more research is needed to determine whether reports integrated into bills have the same level of impact on conservation. Similarly, researchers should investigate the effectiveness of electronic forms of delivery (such as email), which can further increase cost savings. Although such forms of delivery are likely to impact fewer households than direct mail for the time being, they promise significant production cost savings. Another approach to increasing the cost effectiveness of feedback reports would be to only send reports to households where there was not a danger of a "boomerang effect" (here, the lowest two deciles of pretreatment energy users).

\section{PSE Experiment}

Experimental design. In October 2008 Puget Sound Energy (PSE) and Positive Energy/oPower launched another energy feedback report experiment in King County, Washington. There were three major differences in program design between the SMUD and PSE studies: first, the reports encompassed both electricity and natural gas, allowing for a fuller picture of what is happening to households' energy use; second, the study included a randomized 
test of report frequency (monthly or quarterly), and did not test envelope size or template type; and third, the study used household-level randomization, which was more robust than the batchlevel randomization used in the SMUD study.

The PSE experiment consisted of approximately 84,000 homes randomly assigned to control and treatment groups. These homes were chosen from PSE's 1.3 million residential customers who met the following criteria:

- Single family homes located in King County, WA

- Exactly one active electric account and one active gas account with PSE

- History for both gas and electric accounts dating to January, 2007

- Matched parcel record available from the King County Assessor's data

- Not identified by the King County Department of Assessments as having solar heat

This filter created a pool of approximately 100,000 households that were eligible to participate in the program. Additional exclusions were made to eliminate homes with distant neighbors or with unusual home sizes (so that neighbor comparisons would be more meaningful) and homes that used relatively little energy (less than approximately $80 \mathrm{MBTU}$ ). In order to test the effect of frequency of the reports on home energy consumption, households were also randomly assigned to receive the report on a monthly or quarterly basis in the ratio of 3:1. Unlike in the SMUD case, the PSE reports all used the same template and standard-business envelope size.

The PSE reports were based on the more effective "graphical" template deployed in the SMUD study. Sample elements from the front page of this report are included in Appendix A4a and A4b. However, the PSE report included energy information regarding both electricity and natural gas consumption. In addition to two charts tracking the last twelve months of households $\mathrm{kWh}$ and therm consumption relative to nearby neighbors in similar size homes, the template began with a combined energy cost (CEC) comparison to neighbors. ${ }^{4}$

\footnotetext{
${ }^{4}$ The combined energy cost is an estimate of the cost of electricity and gas used by the household. On the reports the combined energy cost was reported in terms of a price-weighted index (PWI), where PWI $=12.51 *$ therms $+\mathrm{kWh}$. The factor 12.51 represents the kilowatt-equivalent price of one additional therm for a PSE customer. An estimate of the combined energy cost (CEC) can then be found by multiplying the PWI by the approximate price of one kWh, 8 cents. The combined energy cost does not exactly reflect the relative costs to the households because the actual pricing formula took into account other factors (e.g., fixed costs).
} 
PSE Results. Appendix A2 shows that the randomization was successful in producing treatment and control households with similar pre-treatment attributes. The table does reveal some statistically significant differences between the randomly assigned monthly or quarterly groups, but the raw differences in levels was not substantial (for example, in 2007 the average $\mathrm{kWh}$ per day was 30.2 and 30.5 for the monthly and quarterly households respectively). Only $1 \%$ of the treatment group opted out of receiving the reports, which, as in the SMUD experiment, suggests that the following intent to treat estimates will be nearly identical to treatment on the treated effects. About $2 \%$ of both the control and treatment households closed their accounts during the experiment because they moved.

Figures $7 \mathrm{a}$ and $7 \mathrm{~b}$ report the results of regressions of the log of monthly average $\mathrm{kWh}$ per day and therms per day usage on a treatment indicator and a constant. Unlike SMUD, where census-tract level randomization created some substantial pre-experiment differences between treatment and control households, the PSE data show no substantial differences in preexperiment usage. All differences between the control and treatment groups for pre-experiment usage, as expected, were statistically insignificant and close to $0 \%$. As Figures $7 \mathrm{a}$ and $7 \mathrm{~b}$ show, however, the treatment households reduced their use of both electrical and natural gas energy relative to the control households in November 2008, after the reports were sent out first on October 20, 2008. As in SMUD, the rapidity of the decrease in electricity use may indicate that the reductions in energy may flow largely from behavioral rather than durable changes.

Table 3 displays the results of stacked monthly regressions (analogous to the SMUD regressions in Table 1) on approximately 1.4 million household-month observations. The regressions are run on the log of three measures of energy use: average monthly $\mathrm{kWh}$ per day, average monthly therms per day, and the combined energy cost (CEC). As in the SMUD Table 1, we report the results of parallel regressions with and without controls for house demographics (such as square footage, age of house, house value), household demographics (such as past energy usage), month, and cooling degree days and heating degree days. As with the SMUD data, the estimated treatment effects are quite robust to the inclusion of ancillary controls. On average, households in the treatment group reduced $\mathrm{kWh}$ usage by $1.2 \%$, therm usage by $1.2 \%$, and a combined price-weighted usage by $1.1 \%$ compared to the control group. One potential explanation for why this figure is lower than the SMUD average is that the experiment has been 
running for a shorter time. There is evidence, as shown in Figures 7a and 7b (discussed below), that the effect may continue to increase.

One advantage of this experiment is that PSE collects daily data on energy usage, with the aid of an automated meter read system called CellNet. Figure 8 reports the results of a regression (with the Table 3 controls) of household-day energy usage where the treatment variable from Table 3 (Treatment $\mathrm{x}$ After first mailing) was interacted with day of week indicators. The figure shows that the lion's share of treatment impact, 38\%, comes from Sunday and Monday (12:00 AM Sunday morning to 11:59 PM Monday night). It may be that the energy savings is even more tightly concentrated in the weekend, with the bulk of the "Monday" savings occurring during the night between Sunday and Monday. For example, if a person decides to turn her thermostat down on Sunday, she may leave whatever setting she has chosen on all night. The evidence that the bulk of the savings is happening on two contiguous days roughly overlapping with the weekend suggests that the primary impact of the energy reports may not be driven by durable conservation efforts, but is instead from increased mindfulness of energy consumption on the weekends. On the other hand, it may be that increased savings on the weekends could be the result of durable, one-time actions as well. For example, if an individual buys a new energyefficient washing machine, and she does the bulk of her laundry on the weekends, she would show the greatest percentage drop in energy on the weekends.

As already discussed, in the SMUD experiment, as shown in Figure 4, those who received the report monthly saved more electricity than those who received it quarterly. However, in SMUD only the lower (pre-treatment) energy-using households were assigned to the quarterly treatment group, leading to the possibility that the smaller estimated quarterly treatment effect was driven by lower pre-treatment energy usage. In the PSE experiment, however, with randomized monthly and quarterly recipients, we are better able to gauge the causal impact of report frequency. Figure 9 shows the results of a regression interacting the treatment effect (Treatment $\mathrm{x}$ After first mailing) with report frequency indicators. For $\mathrm{kWh}$, monthly recipients reduce their usage by about $1.25 \%$ and quarterly recipients reduce their usage of about $1.05 \%$ However, for therms, both quarterly recipients reduce their usage about $1.2 \%$, with the quarterly households reducing slightly more than the monthly. In terms of the combined energy cost, the monthly group shows a slight improvement over the quarterly group, with the monthly group reducing $1.2 \%$ and quarterly group reducing $1.05 \%$. On net, quarterly treatment 
effects are statistically indistinguishable from monthly effects. Given that quarterly reports are just as effective, and cost less to produce and mail, they appear to be the more efficient intervention.

The PSE data also allows us to investigate how the reductions in energy use change across the month, and observe how effects may vary based on proximity to the time the most recent report was sent out. Figures 10a and 10b report the results of a series of regressions (using full Table 3 controls) calculating the treatment effect in terms of $\mathrm{kWh}$ and therms for particular weeks before and after the experiment began. Figure 10a reports the week by week treatment effects on $\mathrm{kWh}$ and therms for recipients of monthly reports. The vertical lines denote the approximate delivery dates of the reports. All 6 mailings after the first mailing had treatment effects that were statistically lower than zero for both $\mathrm{kWh}$ and therms. Figure 10b analogously reports the weekly treatment effects for quarterly report recipients on $\mathrm{kWh}$ and therms. After the first mailing, $52 \%$ of the treatment effects observed on therms were statistically lower than zero for therms, and $77 \%$ of the treatment effects for $\mathrm{kWh}$ were statistically significant $(\mathrm{p} .<.05)$ reductions. Somewhat contrary to our expectations, there is no consistent or pronounced retrenchment for either monthly or quarterly recipients as the time from last report increasesalthough the reductions for the smaller quarterly recipients sample are less precisely measured. The lack of retrenchment suggests that the energy reductions may in large part be driven by durable behaviors, the effects of which would not wane with time; yet, as there is some retrenchment (such as in the electricity usage of quarterly recipients after the second report was received), some of the effect appears to be driven by non-durable behavior.

As in the SMUD experiment, we again see larger treatment effects for lower house value quintiles. Figure 11 shows that the lower three quintiles perform at or below the average reduction of $1.1 \%$. Again, all quintiles saw a reduction, but in the two highest quintiles, the treatment reduction was not as pronounced.

Figure 12 reports the results of a regression (with the full set of controls) interacting the treatment effect with pretreatment energy usage deciles (based on household energy usage for the twelve months prior to the beginning of the experiment, adjusted for house size), with the reductions reported relative to control households in the same usage deciles. We see that in the PSE data the treatment effect is even more strongly correlated with the pretreatment energy usage. As in SMUD, we observe that the lower half of pretreatment energy users reduce usage 
less than the average reduction of $1.1 \%$ (in fact, for the 3 smallest deciles we estimate statistically significant increases in energy usage) while the higher half of pretreatment energy users reduce more than the average. Here the range of effects is wider than in the SMUD experiment, with the lowest pretreatment decile increasing usage by $3.4 \%$ (suggesting a more pronounced "boomerang" effect) and the highest pretreatment decile decreasing use by $6.0 \%$. As mentioned earlier, these findings contradict Schultz, Nolan, Cialdini, Goldstein, and Griskevicius (2007), but do not give significant cause for concern as programs based on the treatment can be controlled so that the lowest energy users do not receive reports.

Finally, Table 4 assesses the potential economic and environmental impact if reports were sent to all households in PSE's customer base. Per household, monthly recipients save nearly $\$ 14$ a year from $\mathrm{kWh}$ reduction and $\$ 11$ a year from therms reduction for a total of nearly \$25 saving a year. Quarterly recipients are only slightly behind, with total yearly savings of $\$ 22.28$ (\$11.19 from $\mathrm{kWh}$ and $\$ 11.09$ from therms). With over 930,000 households receiving electric service and over 681,000 households receiving gas service from PSE, PSE customers would stand to save annually \$23 million from monthly reports and \$20.7 million from quarterly reports per year. In environmental terms this projected customer-base-wide savings from quarterly reports is the equivalent to saving the carbon emissions of 14.3 million gallons of gas. PSE households save \$2.06 per mailing for the monthly reports and \$5.57 per mailing for the quarterly reports. As we mentioned in the SMUD cost and impact analysis above, more research is needed into alternative delivery mechanisms for the reports, such as integration into the bill and electronic mail, in order to determine the most efficient and effective channels of communication. Selectively mailing reports only to households where we did not expect a "boomerang" effect would also increase the efficiency of the treatment.

\section{Conclusion}

Both the PSE and SMUD experiments reveal that Positive Energy/oPower peer comparison reports cause significant reductions in home energy use, confirming the direction of the reductions found by Schultz, Wesley, Nolan, Cialdini, Goldstein, and Griskevicius (2007) in their earlier study in San Marcos. The PSE and SMUD experiments show that the effects of the report continue to be strong, up to seven and twelve months after the households begin to receive 
reports, respectively. The experiments analyzed here do contradict the findings of the San Marcos study to the extent we found a "boomerang" effect for both SMUD and PSE. The boomerang effects are not problematic, however, as reports can be targeted only at households where a boomerang effect is not expected. The experiments also teach us more about the most effective and efficient methods of designing the reporting system. In the SMUD experiment, out of four possible types of envelope size and report type combinations, the most effective was a graphical version of the report sent in a number 10 standard business size envelope. In the PSE experiment, perhaps surprisingly, sending the reports monthly did not have a significantly greater effect than sending them quarterly.

The experiments also reveal interesting dynamics about how different demographics were affected. In both experiments, households in the treatment group with lower house values saved more, on average, than households with higher house values. Also in both experiments, households with higher pre-treatment energy use saved more than households with lower pretreatment energy use. The experiments also provide some evidence about the types of behavior that may be driving energy reductions, although more research is needed in this area. In both the SMUD and PSE studies, the significant reductions achieved in the period immediately after the first reports are sent out may suggest that changes may be behavioral rather than durable. Further supporting the idea that changes are behavioral is the fact that in the PSE experiment, the treatment group reduces its energy use more in a two day period roughly overlapping with the weekend, suggesting that reductions are caused by increased mindfulness, although the results are not conclusive. However, we also learn that the treatment effect does not wane as the time from the report increases, but instead is relatively smooth over the entire month or quarter, which may indicate that energy reductions are caused by more durable changes.

The Positive Energy/oPower experiments suggest that governmental entities should consider mandating or incentivizing peer comparison reporting. As we have shown in our simple calculations above, peer comparison reports can create significant net cost and carbon savings, benefiting both individual households and the environment. The efficiency of savings would be even more pronounced - and possible "boomerang effects" averted - if comparative information were only mandated for those who consume the most energy. Although some utilities, such as those that are publically owned (like SMUD), or private but regulated (like PSE), are beginning to provide such feedback, often utilities do not have adequate incentives to reduce energy 
consumption on their own. Government officials should also consider investing in scientifically designed studies that could increase knowledge in this area, such as determining the cost effectiveness of sending peer feedback inside the regular utility bill.

Finally, the Positive Energy/oPower experiments suggest that privately-delivered peer comparison feedback, such as direct mailings, might prove an effective tool in a range of other situations. There are endless ways public or private entities might employ such feedback to drive desired behavior. Schools might mail parents reports of how many absences or times late their children had compared to peers. Dentists might send mailings to their infrequent visitors indicating how often typical patients come in for cleanings. A gym might inform its lazier patrons of how often typical members work out. Government might even step in to require private entities conduct this type of reporting where it believes there are significant welfare gains. To take one example, the federal government might require that employers inform lowsaving employees how much more their peers are saving in the company 401(k) plan. As these preliminary examples show, the area of peer comparison feedback is ripe for innovation and experimentation. 


\section{References}

Cialdini, Robert B., Carl A. Kallgren, and Raymond R. Reno. 1991. A Focus Theory of Normative Conduct: a Theoretical Refinement and Reevaluation of the Role of Norms in Human Behavior. In Advances in Experimental Social Psychology, ed. M. P. Zanna 24, 201 234. New York, NY: Academic.

Goldstein, Noah J., Robert B. Cialdini, and Vladas Griskevicius. 2008. A Room with a Viewpoint: Using Social Norms to Motivate Environmental Conservation in Hotels, Journal of Consumer Research 35:3, 472-482.

Fischer, Corinna. 2008. Feedback on Household Electricity Consumption: a Tool for Saving Energy?, Energy Efficiency 1, 79-104.

Schultz, P. Wesley, Jessica M. Nolan, Robert B. Cialdini, Noah J. Goldstein, and Vladas Griskevicius. 2007. The Constructive, Destructive, and Reconstructive Power of Social Norms. Psychological Science 18, $429-34$. 

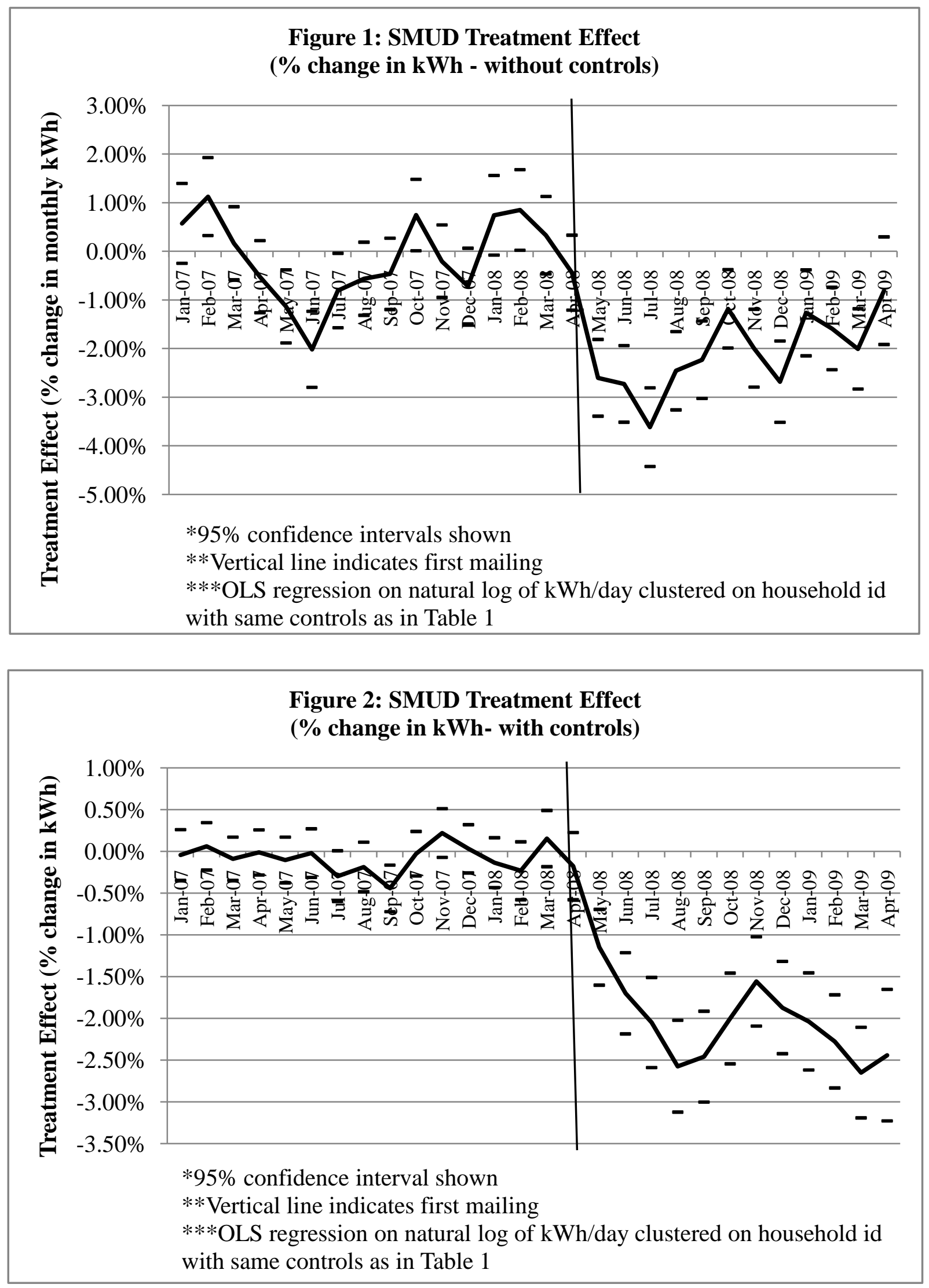
Table 1: SMUD OLS Regression of log household monthly average kWh/day, clustering on household id

\begin{tabular}{|c|c|c|}
\hline & $\begin{array}{l}\text { No controls } \\
n=2,262,815\end{array}$ & $\begin{array}{c}\text { With Controls } \\
\mathbf{n}=\mathbf{1 , 5 8 5 , 4 9 0}\end{array}$ \\
\hline Treatment household & -0.001 & 0.000 \\
\hline After first mailing (April '08) & $-0.018 * * *$ & $0.078 * * *$ \\
\hline Treatment x After first mailing & $-0.020 * * *$ & $-0.021 * * *$ \\
\hline Narrative template & & 0.001 \\
\hline $6 \times 9$ envelope & & 0.001 \\
\hline Quarterly recipients & & $-0.117 * * *$ \\
\hline Cooling degree days & & $0.002 * * *$ \\
\hline Heating degree days & & $0.001 * * *$ \\
\hline House square foot & & $0.000 * * *$ \\
\hline House age & & $0.000 * *$ \\
\hline Pool & & $0.048 * * *$ \\
\hline Spa & & -0.003 \\
\hline House value & & $0.000 * * *$ \\
\hline Gas heat & & $0.033 * *$ \\
\hline kWh/day usage in 2006 & & $0.783 * * *$ \\
\hline Length of residence & & $-0.001 * * *$ \\
\hline Number in residence & & $0.008 * * *$ \\
\hline Head of household age effects & no & yes \\
\hline Income quartile effects & no & yes \\
\hline Affluence effects + & no & yes \\
\hline Proprietary segment effects++ & no & yes \\
\hline Census tracts fixed effects & no & yes \\
\hline Month Fixed Effects & no & yes \\
\hline R-squared & 0.001 & 0.706 \\
\hline \multicolumn{3}{|c|}{$\begin{array}{l}\text { +Ten Affluence groups were created by Direct Group } \\
++ \text { Proprietary segment groups created by Positive Energy based on } \\
\text { house characteristics } \\
* \text { significance at the } 90 \% \text { level } \\
* * \text { significance at the } 95 \% \text { level } \\
* * * \text { significance at the } 99 \% \text { level }\end{array}$} \\
\hline
\end{tabular}



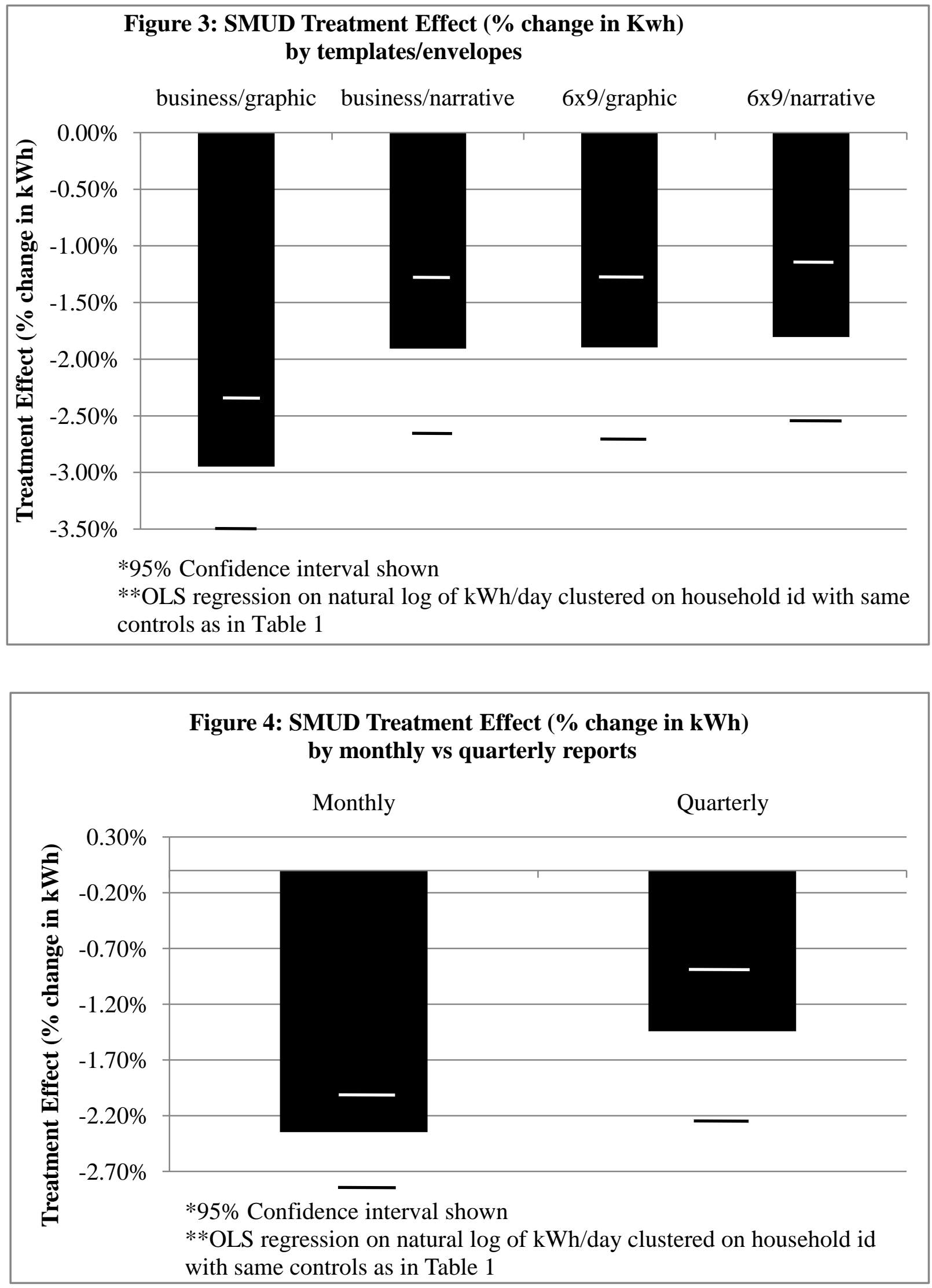

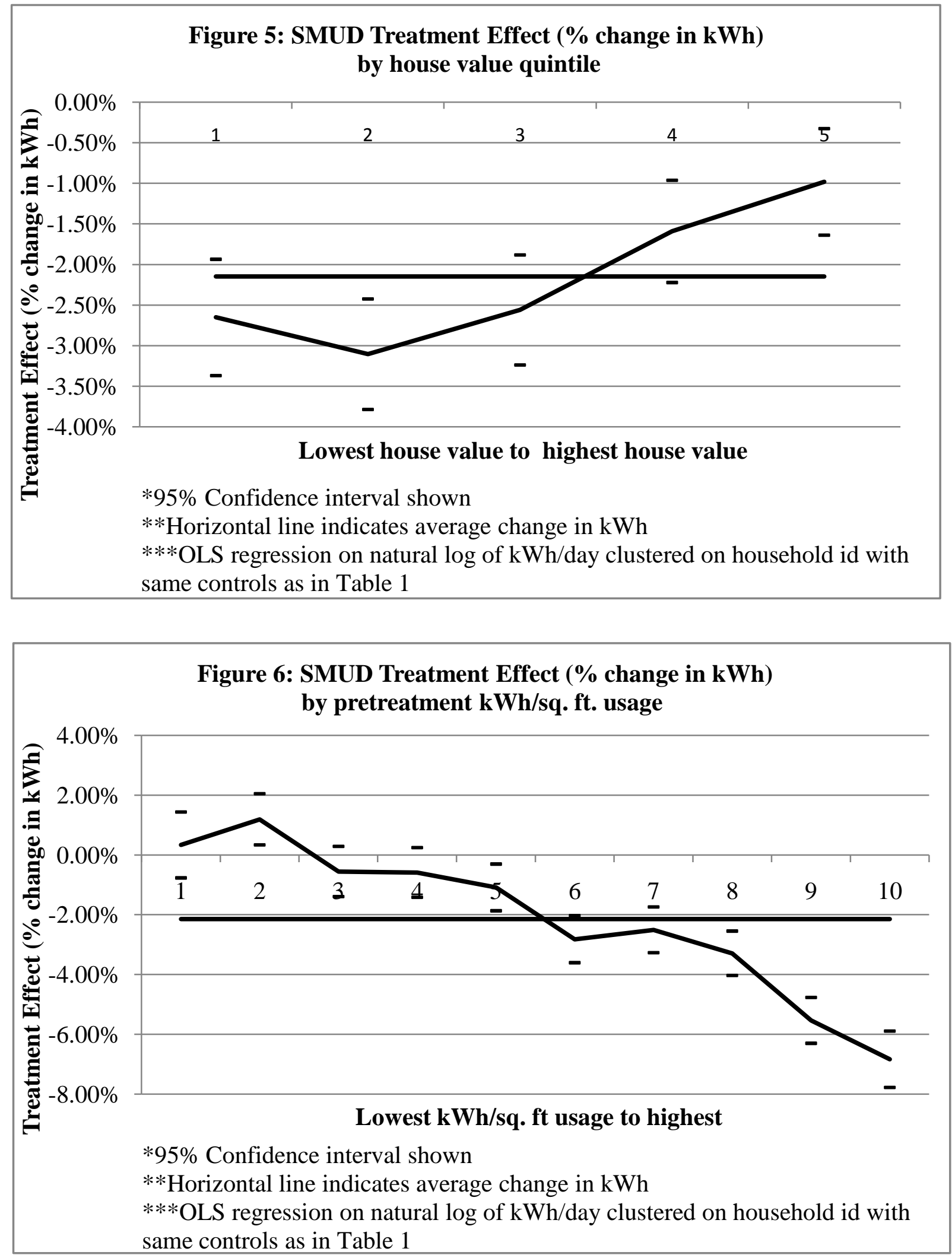
Table 2: SMUD Projected Cost Savings and Environmental Impact

Per Household

Monthly and Quarterly

Reduction kWh/day

Reduction $\mathrm{kWh}$ in a year

187.20

Total savings in a year

$\$$

25.74

Savings per mailing

$\$$ 2.78

For customer base of SMUD

Annual $\mathrm{kWh}$ reduction

$110,917,005$

Annual reduction in metric tons $\mathrm{CO} 2 *$

79,638

Annual reduction in gallons of gas**

$9,039,547$

Annual savings

$15,250,601$

*Based on $7.18 \times 10-4$ metric tons $\mathrm{CO} 2 / \mathrm{kWh}$ calculated by the EPA

$* *$ Based on $8.81 * 10-3$ metric tons $\mathrm{CO} 2 /$ gallon calculated by the EPA 

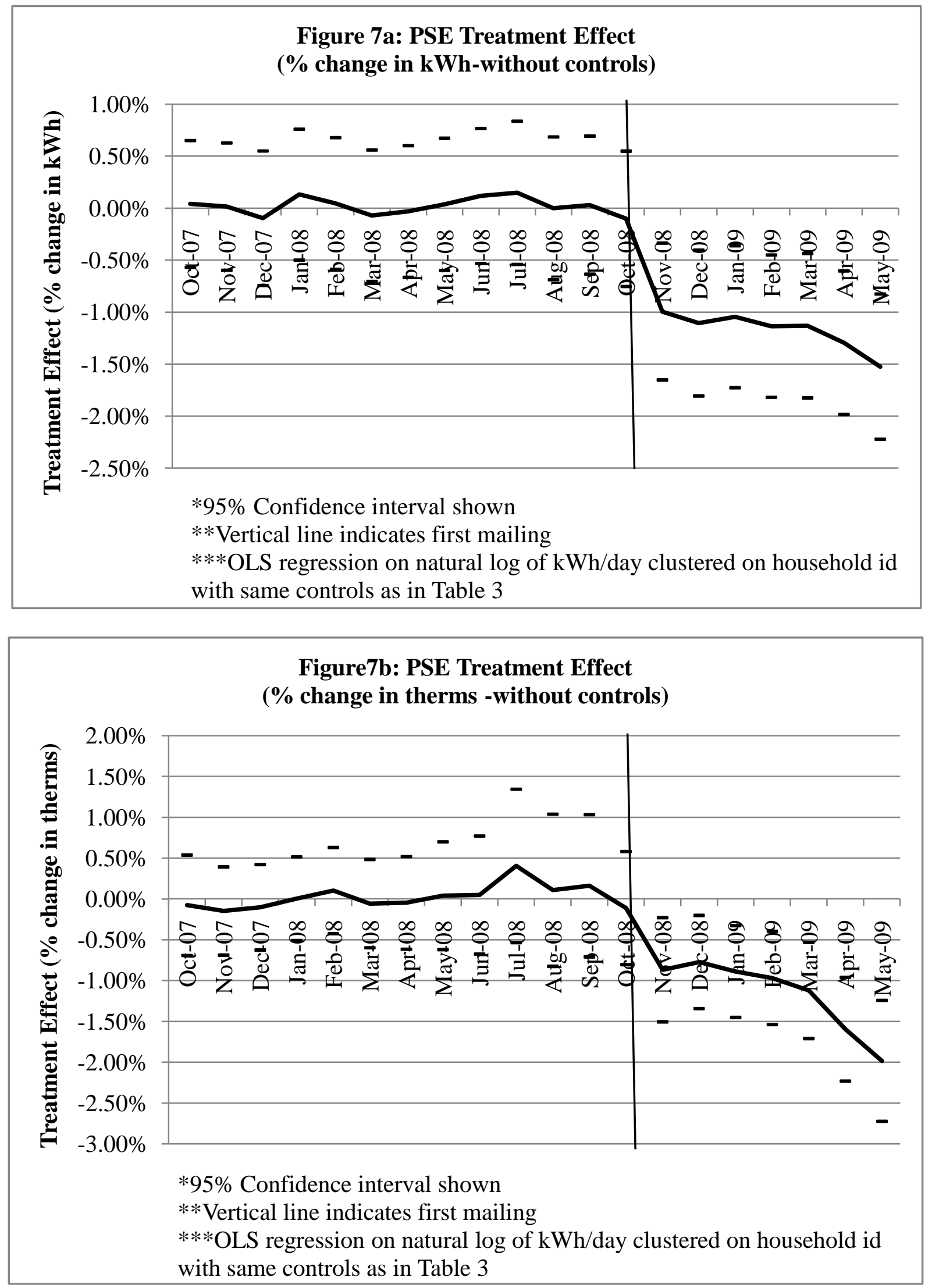


\begin{tabular}{|c|c|c|c|c|c|c|}
\hline & $\begin{array}{l}\text { kWh/day } \\
\text { (without } \\
\text { controls) }\end{array}$ & \begin{tabular}{|c|}
$\mathrm{kWh} / \mathrm{day}$ \\
(with controls) \\
$\mathrm{n}=\mathbf{1 4 1 9 9 4 9}$ \\
\end{tabular} & $\begin{array}{l}\text { therms/day } \\
\text { (without } \\
\text { controls) }\end{array}$ & $\begin{array}{c}\text { therms/day } \\
\text { (with controls) } \\
n=1410933\end{array}$ & $\begin{array}{c}\text { CEC/day } \\
\text { (without controls) } \\
\mathbf{n}=\mathbf{1 4 2 0 3 9 1} \\
\end{array}$ & $\begin{array}{c}\text { CEC/day } \\
\text { (with controls) } \\
n=1420145\end{array}$ \\
\hline Treatment household & 0.000 & 0.000 & 0.000 & 0.001 & 0.000 & 0.000 \\
\hline After first mailing (Oct '08) & $0.042 * * *$ & $-0.292 * * *$ & $0.436 * * *$ & $-2.151 * * *$ & $0.218 * * *$ & $-1.005 * * *$ \\
\hline Treatment x After first mailing & $-0.012 * * *$ & $-0.012 * * *$ & $-0.012 * * *$ & $-0.012 * * *$ & $-0.011 * * *$ & $-0.011 * * *$ \\
\hline House square foot & & $0.000 * * *$ & & 0.000 & & $0.000 * * *$ \\
\hline House age & & 0.000 & & $-0.001 * * *$ & & $0.000 * * *$ \\
\hline House value & & 0.000 & & $0.000 * *$ & & $0.000 * * *$ \\
\hline Quarterly recipient & & -0.001 & & 0.000 & & 0.000 \\
\hline Therms usage in 2007 & & $0.000 *$ & & $1.001 * * *$ & & $0.410 * * *$ \\
\hline kWh usage in 2007 & & 0.932 & & -0.001 & & $0.465 * * *$ \\
\hline Cooling degree days & & -0.001 & & $-0.006 * * *$ & & $-0.003 * * *$ \\
\hline Heating degree days & & 0.000 & & $0.005 * * *$ & & $0.002 * * *$ \\
\hline Proprietary segment effects + & no & yes & no & yes & no & yes \\
\hline Month Fixed Effects & no & yes & no & yes & no & yes \\
\hline R-Squared & 0.001 & 0.717 & 0.065 & 0.849 & 0.043 & 0.810 \\
\hline \multicolumn{7}{|c|}{$\begin{array}{l}\text { +Proprietary segment groups created by Positive Energy based on house characteristics } \\
* \text { significance at the } 90 \% \text { level } \\
* * \text { significance at the } 95 \% \text { level } \\
* * * \text { significance at the } 99 \% \text { level }\end{array}$} \\
\hline
\end{tabular}



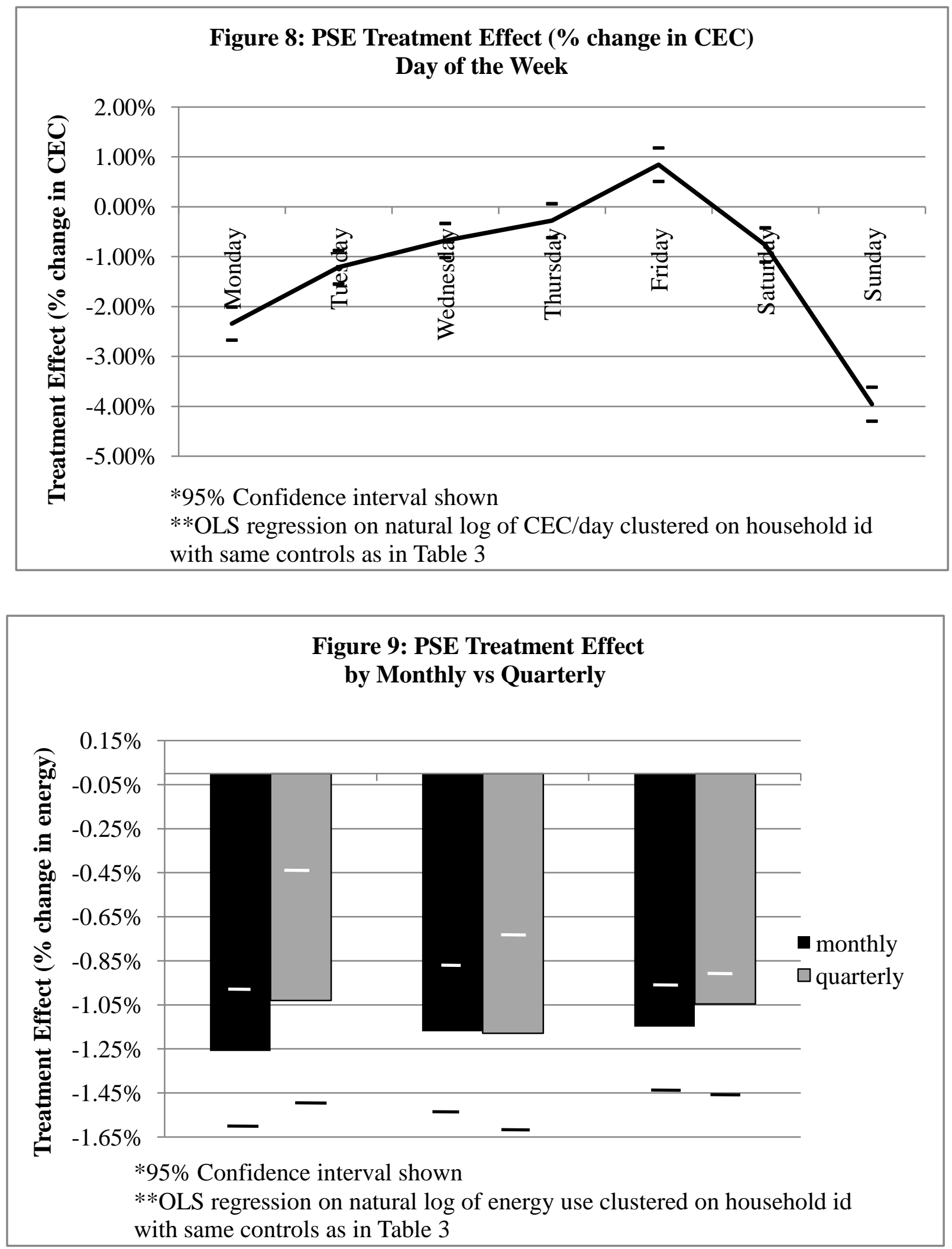


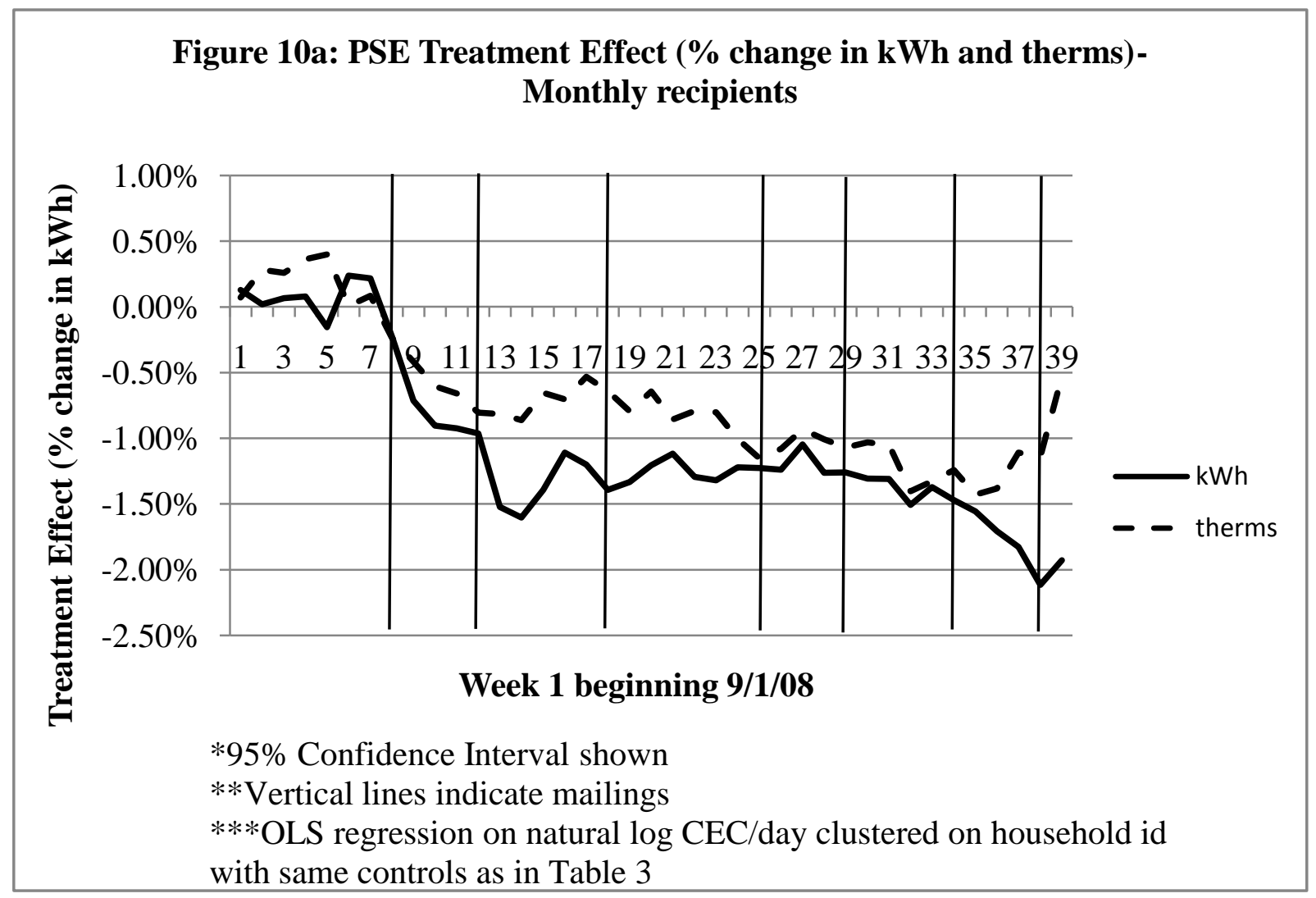

Figure 10b: PSE Treatment Effect (\% change in kwh and therms) Quarterly recipients

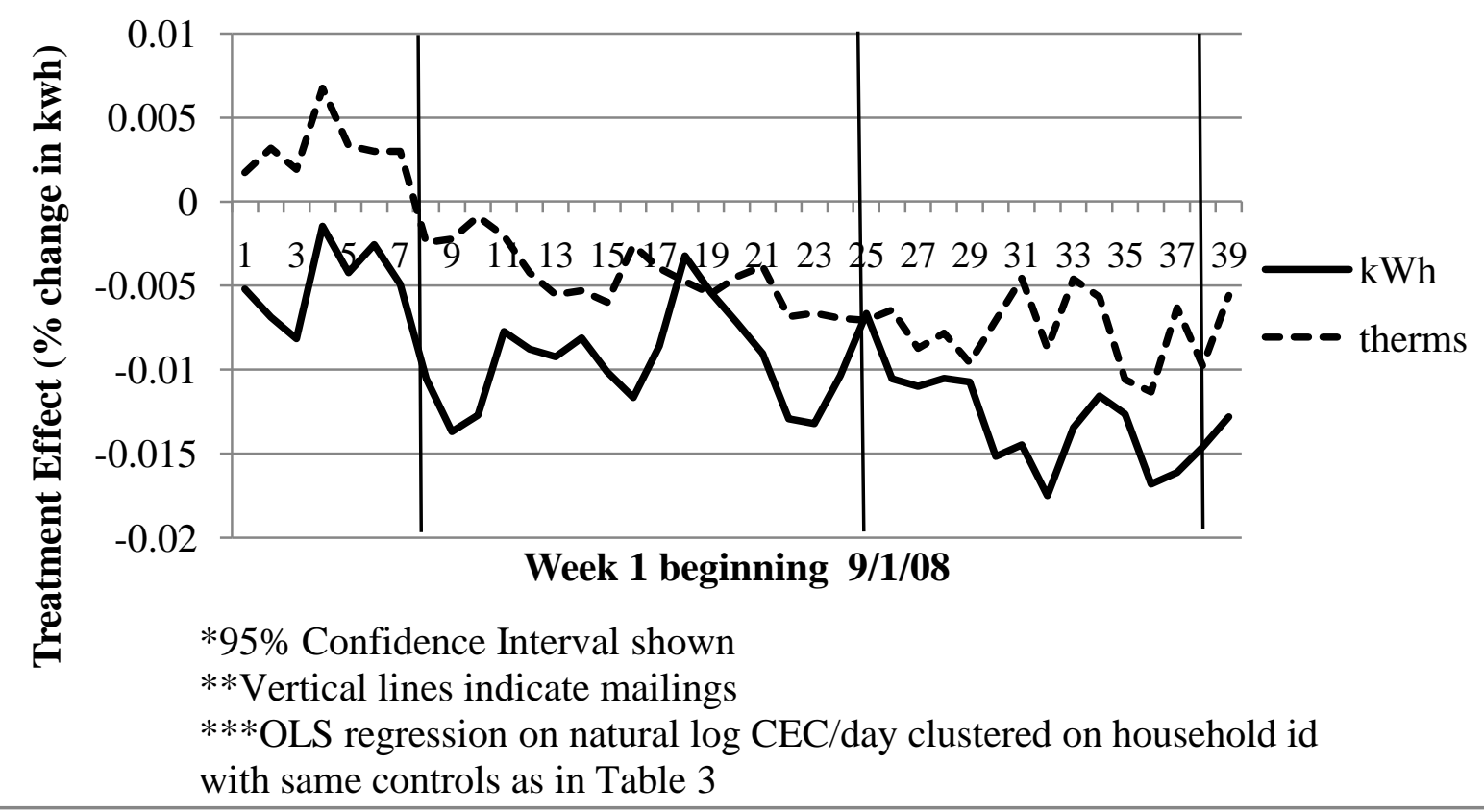



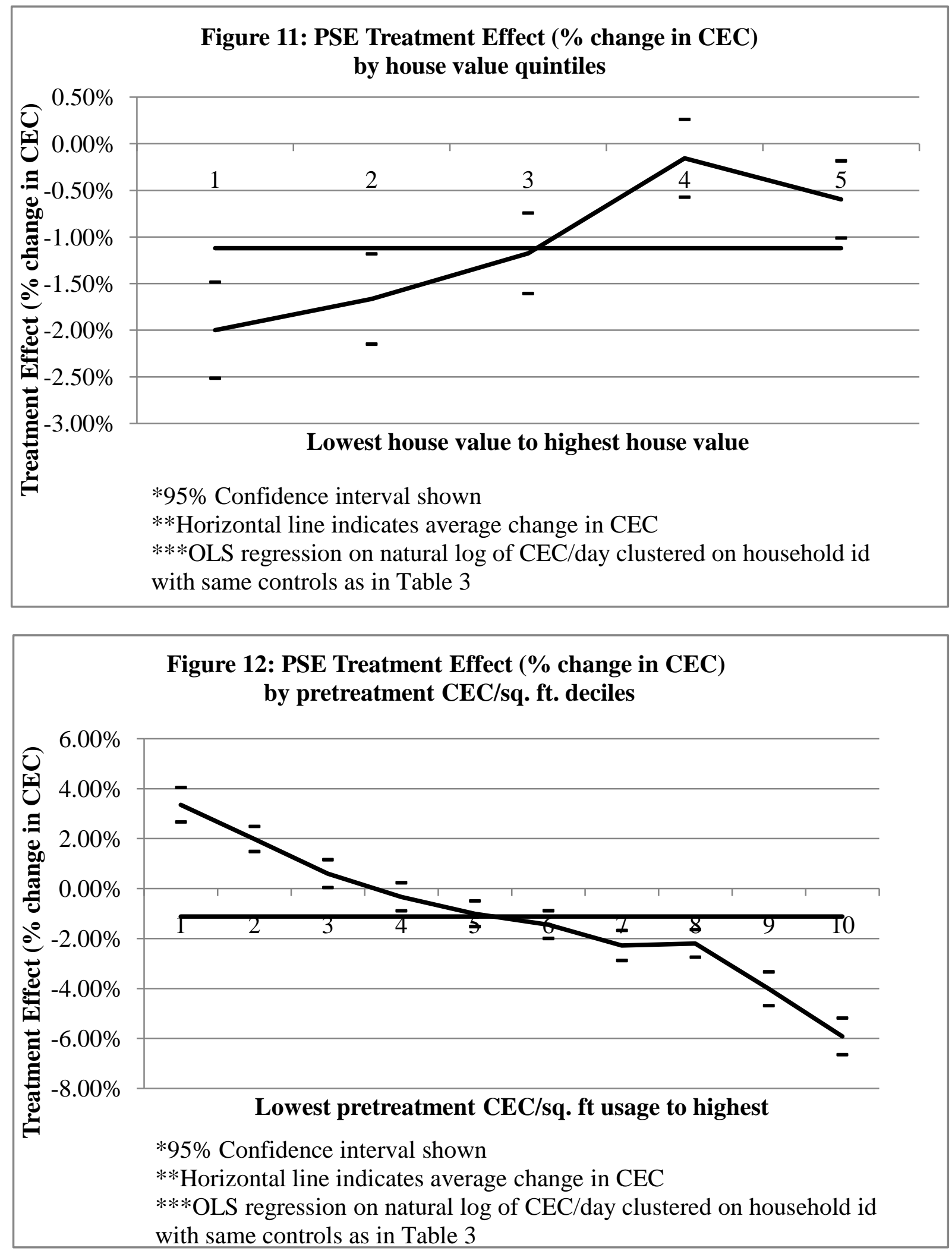


\begin{tabular}{|c|c|c|c|c|}
\hline \multicolumn{5}{|c|}{ Table 4: PSE Projected Cost Savings and Environmental Impact } \\
\hline Per Household - kWh & \multicolumn{2}{|c|}{ Monthly } & \multicolumn{2}{|c|}{ Quarterly } \\
\hline Reduction kWh/day & & 0.41 & & 0.33 \\
\hline Total $\mathrm{kWh}$ reduction in a year & & 148.55 & & 121.53 \\
\hline Total kWh savings in a year & $\$$ & 13.68 & $\$$ & 11.19 \\
\hline \multicolumn{5}{|l|}{ Per Household - therms } \\
\hline Reduction therms/day & & 0.028 & & 0.028 \\
\hline Total therms reduction in a year & & 10.120 & & 10.203 \\
\hline Total therms savings in a year & $\$$ & 11.00 & $\$$ & 11.09 \\
\hline \multicolumn{5}{|l|}{ For customer base of PSE } \\
\hline Annual Savings per household & $\$$ & 24.68 & $\$$ & 22.28 \\
\hline Savings per mailing & $\$$ & 2.06 & $\$$ & 5.57 \\
\hline Annual Savings for Puget Sound & $\$$ & $22,962,206$ & $\$$ & $20,730,469$ \\
\hline Annual savings in metric tons of $\mathrm{CO} 2 *$ & & $3,169,489,576$ & & 115,943 \\
\hline Annual savings in gallons of gas** & & $391,295,009,340$ & & $14,313,900$ \\
\hline
\end{tabular}




\begin{tabular}{|c|c|c|c|c|c|c|c|c|c|c|}
\hline \multicolumn{11}{|c|}{ A1: Mean comparison of all SMUD pre-treatment variables } \\
\hline Variable Name & $\begin{array}{c}\text { Experiment } \\
\mathbf{n}=\mathbf{3 4 5 5 7}\end{array}$ & $\begin{array}{c}\text { Control } \\
n=49570\end{array}$ & & $\begin{array}{c}\text { Graphical } \\
n=41841\end{array}$ & $\begin{array}{l}\text { Narrative } \\
n=41856\end{array}$ & & $\begin{array}{l}0 \text { Envelope } \\
n=42276\end{array}$ & & $\begin{array}{l}9 \text { envelope } \\
\text { l=41851 }\end{array}$ & \\
\hline House square foot & 1,737 & 1,753 & $* * *$ & 1,742 & 1,732 & & 1,731 & & 1,743 & * \\
\hline House age & 35.73 & 36.92 & & 35.79 & 35.66 & & 35.62 & & 35.83 & \\
\hline Pool & 0.21 & 0.22 & $* * *$ & 0.21 & 0.21 & & 0.20 & & 0.21 & $*$ \\
\hline Spa & 0.04 & 0.04 & & 0.04 & 0.04 & & 0.04 & & 0.04 & \\
\hline House value & $\$ 213,584$ & $\$ 215,189$ & & $\$ 214,336$ & $\$ 212,833$ & $\$$ & 212,478 & $\$$ & 214,690 & \\
\hline Gas heat & 0.73 & 0.75 & & 0.73 & 0.73 & & 0.73 & & 0.73 & \\
\hline Account closed & 0.08 & 0.07 & & 0.07 & 0.08 & & 0.08 & & 0.07 & \\
\hline Opt out & 0.02 & . & & 0.02 & 0.02 & & 0.02 & & 0.02 & $*$ \\
\hline Quarterly recipient & 0.29 & 0.29 & $*$ & 0.29 & 0.29 & & 0.29 & & 0.29 & \\
\hline $\mathrm{kWh}$ usage in 2006 & 31.95 & 31.65 & $* * *$ & 31.62 & 31.68 & & 31.71 & & 31.58 & \\
\hline Length of residence & 14.03 & 14.21 & $* *$ & 14.11 & 13.94 & & 13.99 & & 14.06 & \\
\hline Number at residence & 1.93 & 1.93 & & 1.93 & 1.94 & & 1.94 & & 1.93 & \\
\hline Quartile 1 income group & 0.11 & 0.11 & $* *$ & 0.11 & 0.11 & & 0.11 & & 0.11 & \\
\hline Quartile 2 income group & 0.19 & 0.19 & & 0.20 & $0.19 * *$ & & 0.20 & & 0.19 & \\
\hline Quartile 3 income group & 0.16 & 0.16 & & 0.16 & 0.16 & & 0.16 & & 0.17 & \\
\hline Quartile 4 income group & 0.23 & 0.23 & & 0.23 & 0.23 & & 0.23 & & 0.23 & \\
\hline Age- 24 years or less & 0.00 & 0.00 & & 0.00 & 0.00 & & 0.00 & & 0.00 & \\
\hline Age- 25-29 & 0.01 & 0.01 & & 0.01 & 0.01 & & 0.01 & & 0.01 & \\
\hline Age- $30-34$ & 0.03 & 0.03 & & 0.03 & 0.03 & & 0.03 & & 0.03 & \\
\hline Age- $35-39$ & 0.06 & 0.05 & & 0.05 & 0.06 & & 0.06 & & 0.05 & \\
\hline Age- $40-44$ & 0.07 & 0.07 & & 0.07 & 0.07 & & 0.07 & & 0.07 & \\
\hline Age- $45-59$ & 0.09 & 0.09 & & 0.09 & 0.09 & & 0.09 & & 0.09 & \\
\hline Age- $50-54$ & 0.10 & 0.10 & $*$ & 0.10 & 0.10 & & 0.10 & & 0.10 & \\
\hline Age- 55-59 & 0.09 & 0.09 & $* *$ & 0.09 & 0.09 & & 0.10 & & 0.09 & $*$ \\
\hline Age- $60-64$ & 0.07 & 0.07 & & 0.07 & 0.07 & & 0.07 & & 0.07 & \\
\hline Age- $65+$ years & 0.01 & 0.02 & & 0.01 & 0.01 & & 0.01 & & 0.01 & \\
\hline Age- $65-69$ & 0.05 & 0.05 & & 0.05 & 0.05 & & 0.05 & & 0.05 & \\
\hline
\end{tabular}




\begin{tabular}{|c|c|c|c|c|c|c|c|}
\hline A1 continued: Mean & $\begin{array}{c}\text { Earison of all } \mathrm{S} \\
\text { Experiment } \\
\mathbf{n}=\mathbf{3 4 5 5 7}\end{array}$ & $\begin{array}{c}\text { MUD pre- } \\
\text { Control } \\
n=49570\end{array}$ & reati & $\begin{array}{c}\text { ent variable } \\
\text { Graphical } \\
n=41841\end{array}$ & $\begin{array}{l}\text { Narrative } \\
n=41856\end{array}$ & $\begin{array}{c}\text { \#10 Envelope } \\
n=42276\end{array}$ & $\begin{array}{c}\text { 6x9 envelope } \\
n=41851\end{array}$ \\
\hline Age- 70-74 & 0.04 & 0.04 & & 0.04 & 0.04 & 0.04 & 0.04 \\
\hline Age- $75+$ years & 0.07 & 0.07 & & 0.07 & 0.07 & 0.07 & 0.08 \\
\hline kWh/day spent in... & & & & & & & \\
\hline Jan-07 & 36.71 & 36.72 & & 36.69 & 36.74 & 36.78 & 36.65 \\
\hline Feb-07 & 33.10 & 32.95 & & 33.04 & 33.17 & 33.13 & 33.08 \\
\hline Mar-07 & 28.00 & 28.14 & & 27.94 & 28.07 & 28.01 & 27.99 \\
\hline Apr-07 & 24.67 & 24.95 & $* * *$ & 24.63 & 24.72 & 24.72 & 24.63 \\
\hline May-07 & 25.44 & 25.89 & & 25.39 & 25.49 & 25.50 & 25.38 \\
\hline Jun-07 & 28.53 & 29.28 & & 28.48 & 28.58 & 28.58 & 28.48 \\
\hline Jul-07 & 36.92 & 37.32 & $* * *$ & 36.88 & 36.95 & 36.96 & 36.87 \\
\hline Aug-07 & 36.80 & 37.13 & $* * *$ & 36.73 & 36.87 & 36.87 & 36.73 \\
\hline Sep-07 & 37.78 & 38.01 & $*$ & 37.81 & 37.76 & 37.86 & 37.71 \\
\hline Oct-07 & 25.70 & 25.63 & & 25.68 & 25.72 & 25.78 & 25.62 \\
\hline Nov-07 & 25.21 & 25.44 & $* *$ & 25.15 & 25.27 & 25.28 & 25.14 \\
\hline Dec-07 & 30.77 & 31.18 & $* * *$ & 30.69 & 30.86 & 30.79 & 30.76 \\
\hline Jan-08 & 36.07 & 36.00 & & 36.02 & 36.12 & 36.08 & 36.06 \\
\hline Feb-08 & 32.81 & 32.75 & & 32.75 & 32.87 & 32.87 & 32.76 \\
\hline Mar-08 & 27.48 & 27.57 & & 27.47 & 27.49 & 27.53 & 27.43 \\
\hline
\end{tabular}




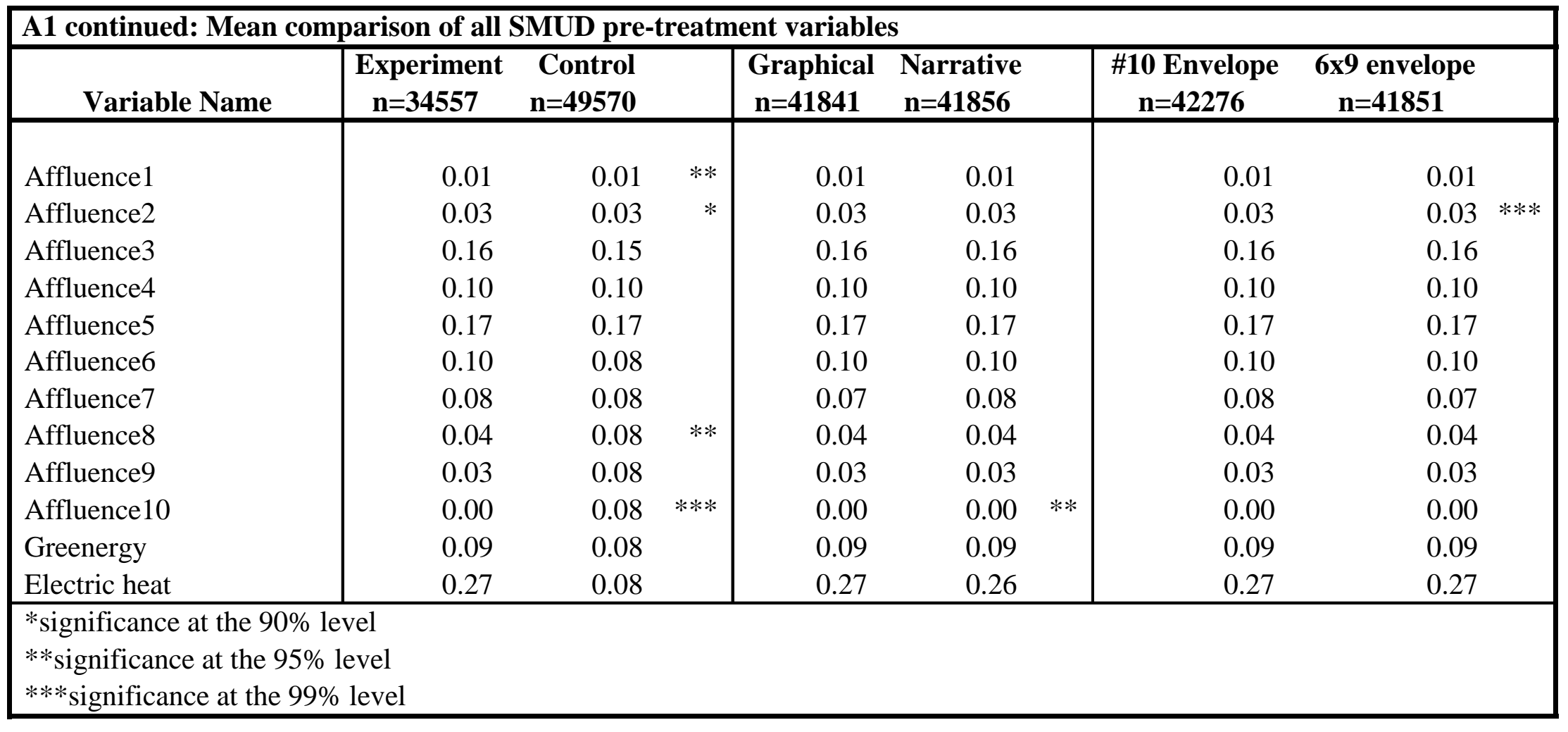




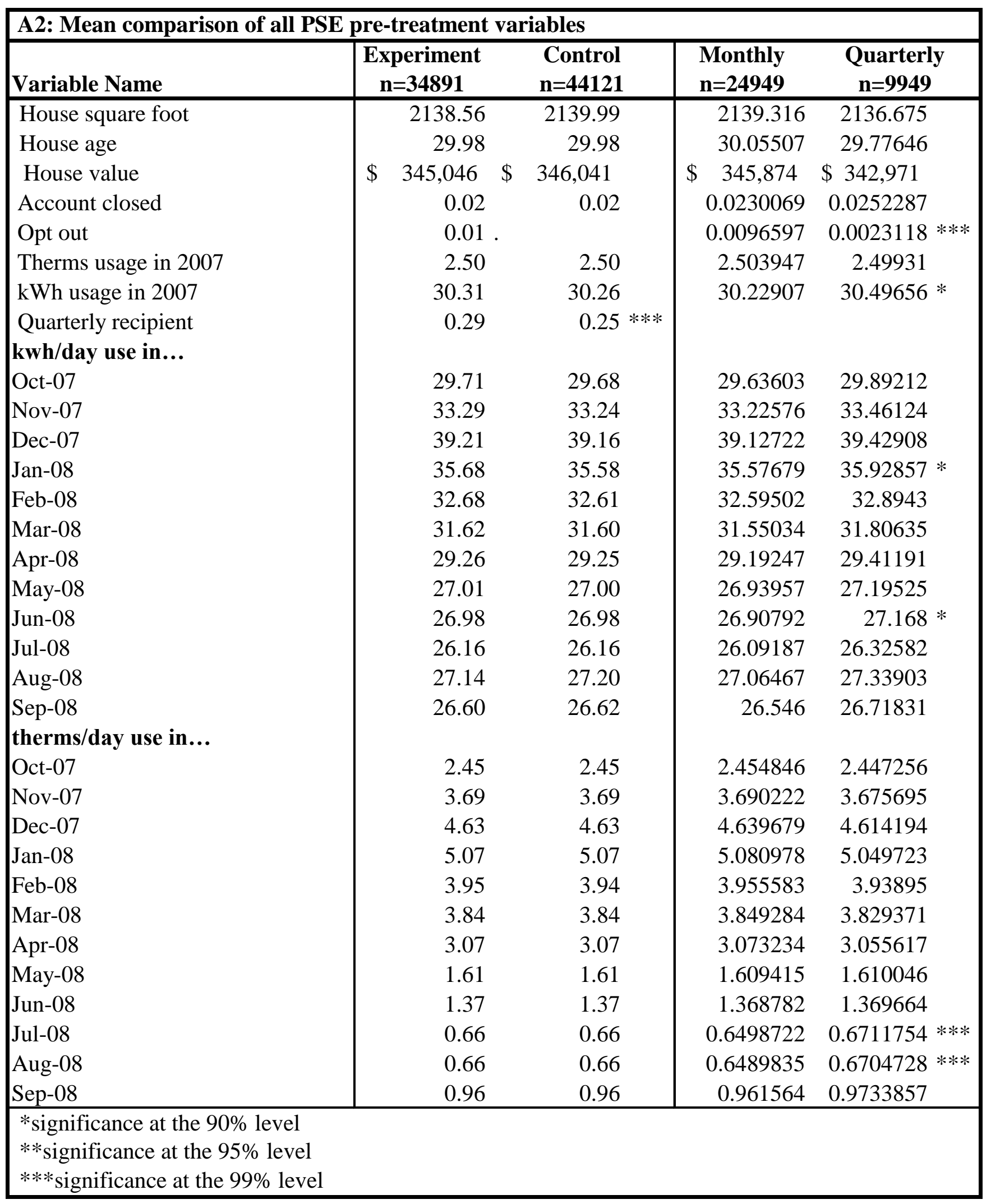




\section{A3a: SMUD sample report, narrative template}

Last month you used $35 \%$ LESS electricity than your efficient neighbors.

Your energy efficiency for the month was: Greatl

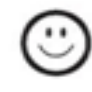

You should feel good about your energy efficiency and the savings this means for you. To save even more energy and cost, see the back of this report for some personalized suggestions to help you improve your efficiency even more.

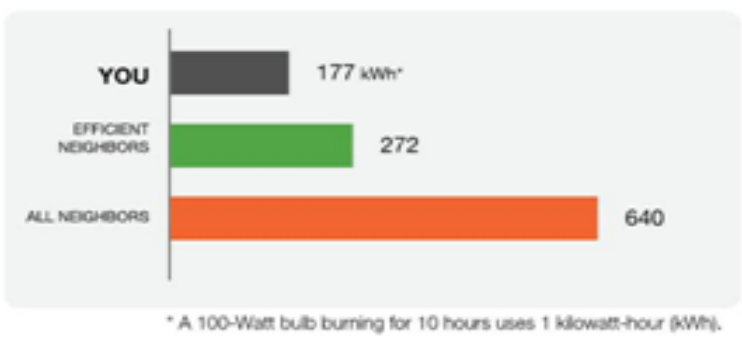

\section{A3b: SMUD sample report, narrative template}

In the last 12 months you used 20\% MORE than your efficient neighbors. At today's rates this COSTS YOU ABOUT \$85 EXTRA PER YEAR.

This means you have a great opportunity to save energy and money in the future.

The summer is a great time to focus on energy efficiency because of the high cost of air conditioning. You can reduce your home cooling costs by replacing your $\mathrm{AC}$ filter, maintaining your $A C$ unit each year, and using fans.

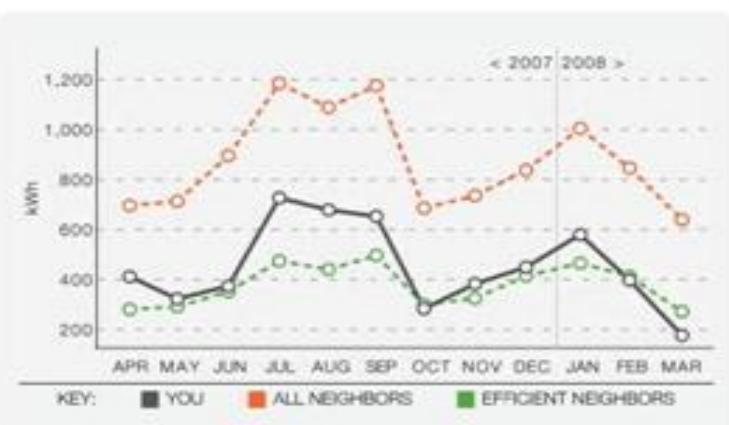


A4a: PSE sample report

August Neighbor Comparison | You used 14\% MORE energy than your neighbors.
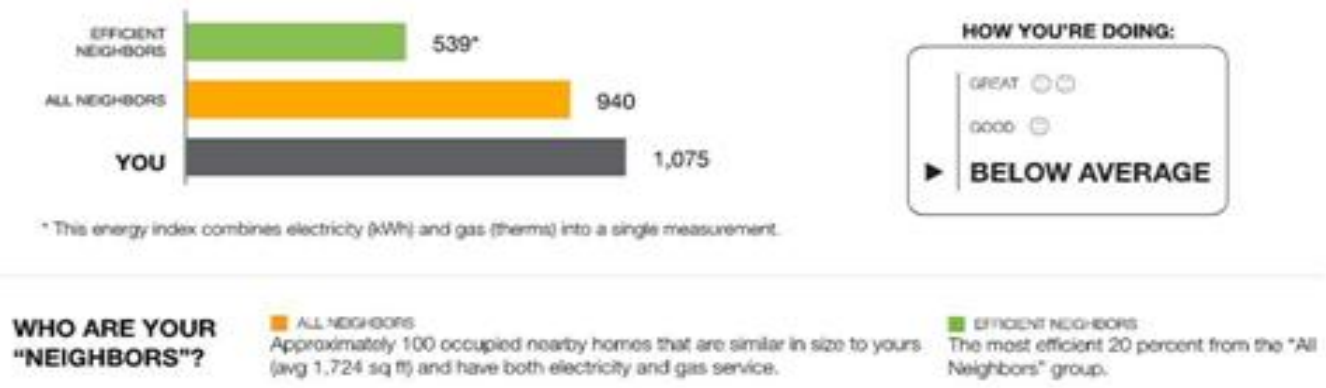

\section{A4b: PSE sample report}
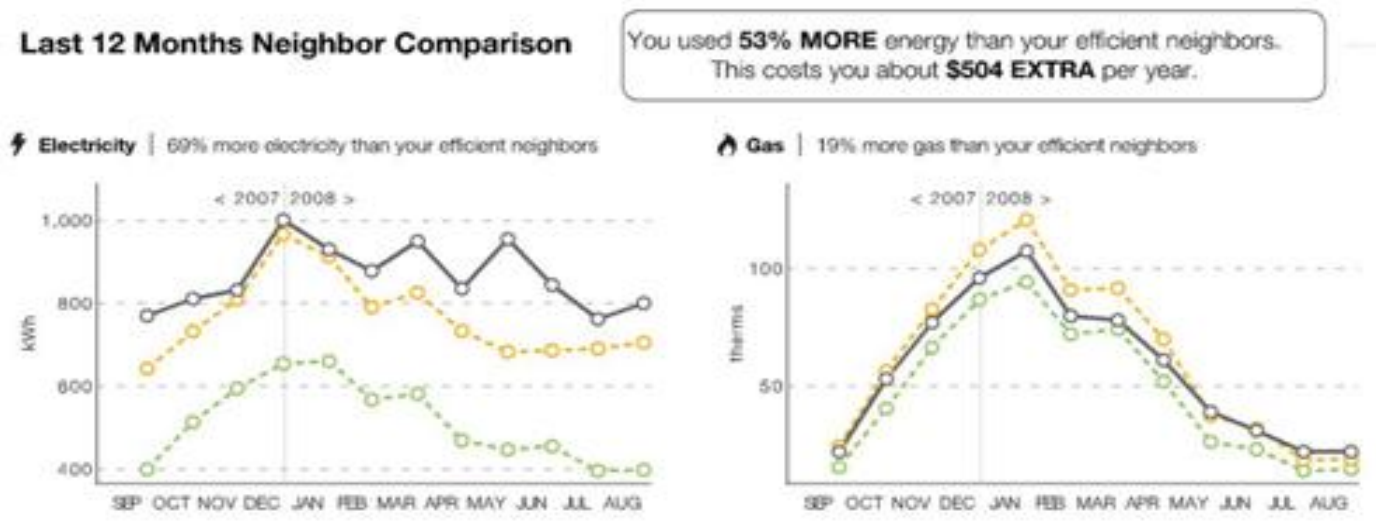
